\title{
Norepinephrine-induced invasion by pancreatic cancer cells is inhibited by propranolol
}

\author{
KUN GUO, QINGYONG MA, LIANCAI WANG, HENGTONG HU, JUNHUI LI, \\ DONG ZHANG and MIN ZHANG \\ Department of Hepatobiliary Surgery, First Affiliated Hospital of Medical College of \\ Xi'an Jiaotong University, 277 West Yanta Road, Xi'an 710061, P.R. China
}

Received May 19, 2009; Accepted June 22, 2009

DOI: 10.3892/or_00000505

\begin{abstract}
Active migration and invasion by cancer cells are a prerequisite for the development of metastases. Recent studies have shown that neurotransmitters are involved in the regulation of cancer cell invasion via $\beta$-adrenoceptors (B-ARs). However, little is known regarding the effect of neurotransmitters on pancreatic cancer cells. The aim of our study was to examine the regulative effect of norepinephrine (NE), which belongs to the group of classical neurotransmitters, on the invasiveness of pancreatic cancer cells and the therapeutic effect of the B-blocker, propranolol, on them. The human pancreatic cancer cell lines, Miapaca-2 and Bxpc-3, were selected for this study, and in both cell lines, $\beta_{1}$-AR and $\beta_{2}$-AR expression was determined by RT-PCR and Western blotting. The invasiveness of pancreatic cancer cells was examined using the Matrigel invasion assay. The concentrations of MMP-2, MMP-9, and VEGF in the culture medium and in the cancer cells were examined by ELISA and RT-PCR, respectively. We observed that NE promoted the invasiveness of Miapaca-2 cells in a concentrationdependent manner, and NE increased the expression of MMP-2, MMP-9, and VEGF. However, these effects could be inhibited by the $\beta$-blocker, propranolol. In conclusion, the development of metastases is not only genetically determined, but is also influenced by NE, which is one of the signal substances present in the tumor environment. This study also provides experimental evidence for the use of Bblockers in the chemoprevention of pancreatic cancer metastasis.
\end{abstract}

\section{Introduction}

More than $90 \%$ of deaths from cancer do not result from the primary tumor, but from the development of metastases (1).

Correspondence to: Dr Qingyong Ma, Department of Hepatobiliary Surgery, First Affiliated Hospital of Medical College of Xi'an Jiaotong University, 277 West Yanta Road, Xi'an 710061, P.R. China

E-mail: qyma56@mail.xjtu.edu.cn

Key words: pancreatic cancer, cell invasion, norepinephrine, $ß$-adrenoceptor, propranolol
Therefore, a vital aim in the treatment of cancer should be to inhibit the spread of tumor cells, including tumor cell migration and invasion, thus inhibiting the development of metastases. However, the complex process and mechanism of metastasis is not well understood to date, but that genetic alterations of the neoplastic cells as well as host factors in the tumor environment are believed to be involved. Genetic mutations theory has been developed by Fearon and Vogelstein for colorectal tumors (2). This theory is supported by the finding that mutations of the tumor suppressor gene, MADH4, occur more frequently in metastatic tumors (3). Host factors promoting cancer metastatic development is based on the finding that signal substances such as ligands to $G$ protein-coupled receptors are capable of regulating the migratory and invasive activity of tumor cells, which is similar to the recruitment and homing of leukocytes in the immune system $(4,5)$. These ligands predominantly consist of 2 groups, namely chemokines and neurotransmitters $(6,7)$.

Norepinephrine (NE) belongs to the group of classical neurotransmitters (6), and it is one of the most potent known stimulators of tumor cell migration (8). Recently, the studies of Sood et al (9) and Lutgendorf et al $(10,11)$ have shown that NE may influence the progression of ovarian cancer by modulating the expression of matrix metalloproteinases (MMPs) and the angiogenic cytokine, VEGF, in ovarian cancer cells. Studies in mice support these observations (12). It has also been indicated that NE can activate the migration of carcinoma cells from cancers of the breast (13), colon (14), and prostate (15). Furthermore, the NE-induced migration of these carcinoma cells has been shown to occur via $ß$-adrenoceptors ( $ß$-ARs) (13-15).

More than 200,000 people die annually from pancreatic cancer in the world, and its 5-year survival rate is still below $5 \%$ (16). The incidence of pancreatic cancer is almost equal to its mortality rate. More than half of pancreatic cancer patients have distant metastasis. The morbidity and mortality from pancreatic cancer is conspicuously associated with metastasis (17). No substantial treatment improvements have been made, and the treatments have little effect on prolonging survival time. The expression of $\beta_{1}-A R$ and $\beta_{2}-A R$ in human pancreatic cancer cell lines and their role in the stimulation of cell proliferation were first described in 2001 (18), and these findings were later extended to show that B-ARs signaling in 
these cells included cAMP-dependent transactivation of the EGFR pathway (19). In our present study, we found that the human pancreatic cell lines, Miapaca-2, Bxpc-3 and PC-2, expressed both $\beta_{1}-A R$ and $\beta_{2}-A R$ (20). However, the role of $B$-ARs in the pancreatic cancer cells is not completely understood, and little is known regarding the effect of NE on pancreatic cancer cells. Therefore, we addressed whether $\mathrm{NE}$ is capable of stimulating metastatic invasion by pancreatic cancer cells and whether this effect can be inhibited by treatment with clinically established B-blockers.

We found that pancreatic cell lines in our present study expressed B-ARs. Previous studies have indicated that NE can promote the migration and invasion of carcinoma cells via B-ARs. Therefore, we hypothesize that NE, which belongs to the group of classical neurotransmitters, may play a role in the metastasis of pancreatic cancer, and B-blockers may be used for the chemoprevention of pancreatic cancer metastasis.

\section{Materials and methods}

Cell line and culture conditions. Human pancreatic cancer cell lines (Miapaca-2 and Bxpc-3) were stored in the Department of Hepatobiliary Surgery, the First Affiliated Hospital of Xi'an Jiaotong University. The cells were cultured in DMEM (Invitrogen, Carlsbad, CA, USA) supplemented with $10 \%$ FBS (Invitrogen), penicillin $(100 \mathrm{U} / \mathrm{ml})$ and streptomycin $(0.1 \mathrm{mg} / \mathrm{ml})$.

Matrigel invasion assay. An invasion assay was performed with a Millicell invasion chamber (Millipore, Billerica, MA, USA). The $8-\mu \mathrm{m}$ pore inserts were coated with $15 \mu \mathrm{g}$ of Matrigel (Becton-Dickinson Labware, Bedford, MA, USA). The cells were first seeded in 12 -well plates at a concentration of $2.5 \times 10^{5}$ per well and were cultured for $24-\mathrm{h}$ treatment with norepinephrine (Sigma, St. Louis, USA) at concentrations of $0.1,1$, and $10 \mu \mathrm{M}$. For the blocking experiments, $1 \mu \mathrm{M}$ propranolol (Sigma) was added to the cell cultures $1 \mathrm{~h}$ before the addition of $10 \mu \mathrm{M}$ norepinephrine. Normal culture medium was added at the bottom chamber to induce the cancer cell lines. Cells $\left(5 \times 10^{4}\right)$ which were pretreated were seeded in the top chamber. The Matrigel invasion chamber was incubated for $24 \mathrm{~h}$ in a humidified tissue culture incubator. Non-invading cells were removed from the top of the Matrigel with a cotton-tipped swab. Invading cells on the bottom surface of filter were stained with Crystal Violet (Boster Biological Technology Ltd., Wuhan, China). Invasion ability was determined by counting the stained cells.

ELISA assays. The concentrations of total MMP-2, total MMP-9, and VEGF from the pancreatic cancer cell lines in the conditioned medium were detected using a commercial ELISA. The serum-free conditioned medium from the cultures of the pancreatic cancer cells was collected at $24 \mathrm{~h}$ following exposure to norepinephrine with or without propranolol. The supernatant was microfuged to remove the debris, and the remainder was then stored at $-80^{\circ} \mathrm{C}$. The samples were thawed only once for analysis. Secretion of MMP-2, MMP-9 and VEGF (Peprotech, Rocky Hill, NJ, USA) were later quantified with ELISA kits per the manufacturer's instructions. Samples were assayed in duplicate.

Reverse transcription-PCR. Total RNA was isolated from the Miapaca-2 and Bxpc-3 cells using TRIzol reagent (Invitrogen Life Technologies) according to the manufacturer's instructions. DNase was used to remove the contaminating genomic DNA after RNA purification. cDNA synthesis was performed by heating $3 \mu \mathrm{g}$ of total RNA with $0.5 \mu \mathrm{g}$ of random primers and dNTP (final concentration, $0.5 \mathrm{mM}$ ) at $65^{\circ} \mathrm{C}$ for $5 \mathrm{~min}$. Reverse transcription was then performed at $42^{\circ} \mathrm{C}$ for $1 \mathrm{~h}$ with this mixture at a final volume of $20 \mu \mathrm{l}$ containing $0.5 \mathrm{M}$ Tris- $\mathrm{HCl}$ ( $\mathrm{pH} 8.0$ ), $0.5 \mathrm{M}$ potassium chloride, $0.05 \mathrm{M} \mathrm{MgCl}_{2}, 40 \mathrm{U}$ RNase inhibitor (MBI Fermentas Life Sciences, Foster, CA), 200 U M-MLV reverse transcriptase (Gibco), and $10 \mathrm{mM}$ dithiothreitol in RNase-free water. PCR amplification was performed on $2 \mu 1$ of the synthesized cDNA under the following conditions: $94^{\circ} \mathrm{C}$ for $3 \mathrm{~min}, 30$ cycles of denaturation for $45 \mathrm{sec}$ at $94^{\circ} \mathrm{C}, 45 \mathrm{sec}$ of annealing at $58^{\circ} \mathrm{C}$, elongation at $72^{\circ} \mathrm{C}$ for $35 \mathrm{sec}$, and extension at $72^{\circ} \mathrm{C}$ for $5 \mathrm{~min}$. Mixtures containing $9 \mu \mathrm{l}$ of the resulting PCR fragments and $1 \mu 1$ of $10 \mathrm{X}$ loading buffer were electrophoresed on a $1.5 \%$ agarose gel in $1 \mathrm{X}$ TAE buffer at $110 \mathrm{~V}$ for $30 \mathrm{~min}$ at room temperature. The resulting straps on the gel were photographed and analyzed using a gel-imaging analyzer. Levels of gene expression were expressed as the ratios of densities between PCR products and B-actin in the same sample. All experiments were repeated three times.

The primers were as follows: MMP-2: forward, 5'-CCG TCG CCC ATC ATC AAG TTC-3' and reverse, 5'-GCA GCC ATA GAA GGT GTT CAG G-3' (90 bp). MMP-9: forward, 5'-TGG TCC TGG TGC TCC TGG TG-3' and reverse, 5'-GCT GCC TGT CGG TGA GAT TGG-3' (111 bp). VEGF: forward, 5'-CTG GGC TGT TCT CGC TTC G-3' and reverse, 5'-CTC TCC TCT TCC TTC TCT TCT TCC-3' (140 bp). $\beta_{1}$-AR: forward, 5'-GGG AGA AGC ATT AGG AGG G-3' and reverse, 5'-CAA GGA AAG CAA GGT GGG-3' (270 bp). $\beta_{2}$-AR: forward, 5'-CAG CAA AGG GAC GAG GTG-3' and reverse, 5'-AAG TAA TGG CAA AGT AGC G-3' (334 bp). B-actin (used as a loading control): forward, 5'-ATC GTG CGT GAC ATT AAG GAG AAG-3' and reverse, 5'-AGG AAG GAA GGC TGG AAG AGT G-3'. All primers were synthesized by Shanghai Sangon Biological Engineering \& Technology and Service Co., Ltd., China.

Protein extraction and Western blotting. Total protein was isolated from $1 \times 10^{7}$ cells with $200 \mu 1$ of ice-cold lysis buffer containing 1\% Nonidet P-40 (NP-40), 50 mM Tris ( $\mathrm{pH} 7.4$ ), $150 \mathrm{mM} \mathrm{NaCl}, 0.1 \%$ sodium dodecyl sulfate (SDS), $0.5 \%$ deoxycholate, $200 \mathrm{mg} / \mathrm{ml}$ phenylmethanesulfonyl fluoride (PMSF), and $50 \mathrm{mg} / \mathrm{ml}$ aprotinin. Insoluble materials were removed by centrifugation at $15,000 \mathrm{x}$ g for $15 \mathrm{~min}$ at $4^{\circ} \mathrm{C}$. The concentration of the extracted protein was measured spectrophotometrically with Coomassie G-250. Cell lysates containing equal amounts of protein were electrophoretically resolved on a denaturing SDS-polyacrylamide gel (12\%), and electrotransferred onto nitrocellulose membranes. The membranes were initially blocked with $5 \%$ non-fat dry milk in Tris-buffered saline (TBS) for $2 \mathrm{~h}$ and then incubated in $\beta_{1}$ adrenergic receptor (1:500) or $\beta_{2}$-adrenergic receptor (1:500) 


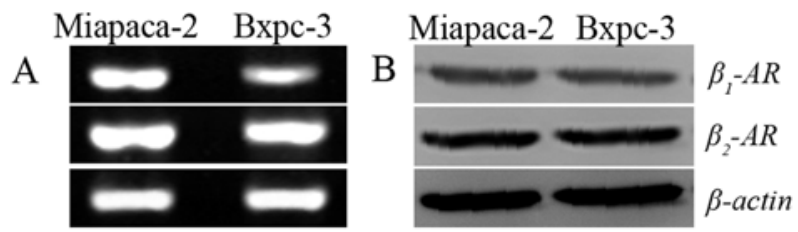

Figure 1. Expression of mRNA and protein for $\beta_{1}-A R$ and $\beta_{2}-A R$ in the human pancreatic cancer cell lines Miapaca- 2 and Bxpc-3 by RT-PCR and Western blotting. In RT-PCR, the $\beta_{1}$ primers amplified a $270 \mathrm{bp}$ fragment, whereas the $B_{2}$ primers amplified a $334 \mathrm{bp}$ fragment (A). In Western blot analysis, $\beta_{1}$-AR and $\beta_{2}$-AR immunoreactivity was visualized as a single band that migrates at approximately 64 and $95 \mathrm{kDa}$, respectively.

primary antibodies (Abcam, Cambridge, MA) at $4^{\circ} \mathrm{C}$ overnight and secondary antibodies for $2 \mathrm{~h}$ at room temperature. The protein bands specific for antibody were visualized by enhanced chemiluminescence associated fluorography. The Western blotting was graded positive if the band of interest was present at the expected molecular weight corresponding to each marker protein. All analyses were done in duplicate.

Statistical analysis. All statistical analyses were performed using the SPSS13.0 software. The results are presented as mean \pm SD of three replicate assays. Differences between the groups were assessed by analysis of variance (ANOVA). $\mathrm{P}<0.05$ was considered to indicate statistical significance.

\section{Results}

Expression of $\beta$-ARs in the human pancreatic cancer cells. RT-PCR analysis revealed that both $\beta_{1}$-AR and $\beta_{2}$-AR were expressed by both Miapaca- 2 and Bxpc-3 cell lines (Fig. 1A). Western blot analysis showed $\beta_{1}$-AR immunoreactivity was visualized as a single band that migrates at $\sim 64 \mathrm{kDa}$, whereas $\beta_{2}$-AR migrates at $95 \mathrm{kDa}$ and the $\beta_{2}$-AR protein yielding the more prominent band (Fig. 1B).

Increased cell invasion of human pancreatic cancer cells by NE is inhibited by $\beta$-blocker, propranolol. The effect of treatment with NE on pancreatic cancer cell line Miapaca-2 was studied in vitro. The number of invasive cells pretreated with NE increased in a concentration-dependent manner (Fig. 2A-D). Significant effect on cell invasiveness with a $\sim 2$.1-fold and $\sim 2.8$-fold increase as compared to control in case of $1 \mu \mathrm{M}$ and $10 \mu \mathrm{M}$ of $\mathrm{NE}$, respectively. To further determine whether the B-ARs mediated the effect of NE on the invasiveness of the pancreatic cancer cells, we pretreated the Miapaca-2 cells with the broad-spectrum $\beta$-blocker, propranolol $(1 \mu \mathrm{M}), 1 \mathrm{~h}$ before the addition of $10 \mu \mathrm{M} \mathrm{NE}$ for $24 \mathrm{~h}$. Our results showed that propranolol reduced the number of invaded pancreatic cancer cells of NE-stimulated by $\sim 3.5$-fold (Fig. 2). These results suggest that exogenous NE stimulated invasiveness by pancreatic cancer cells and propranolol blocked NE-mediated stimulation of the invasiveness of human pancreatic cancer cells.
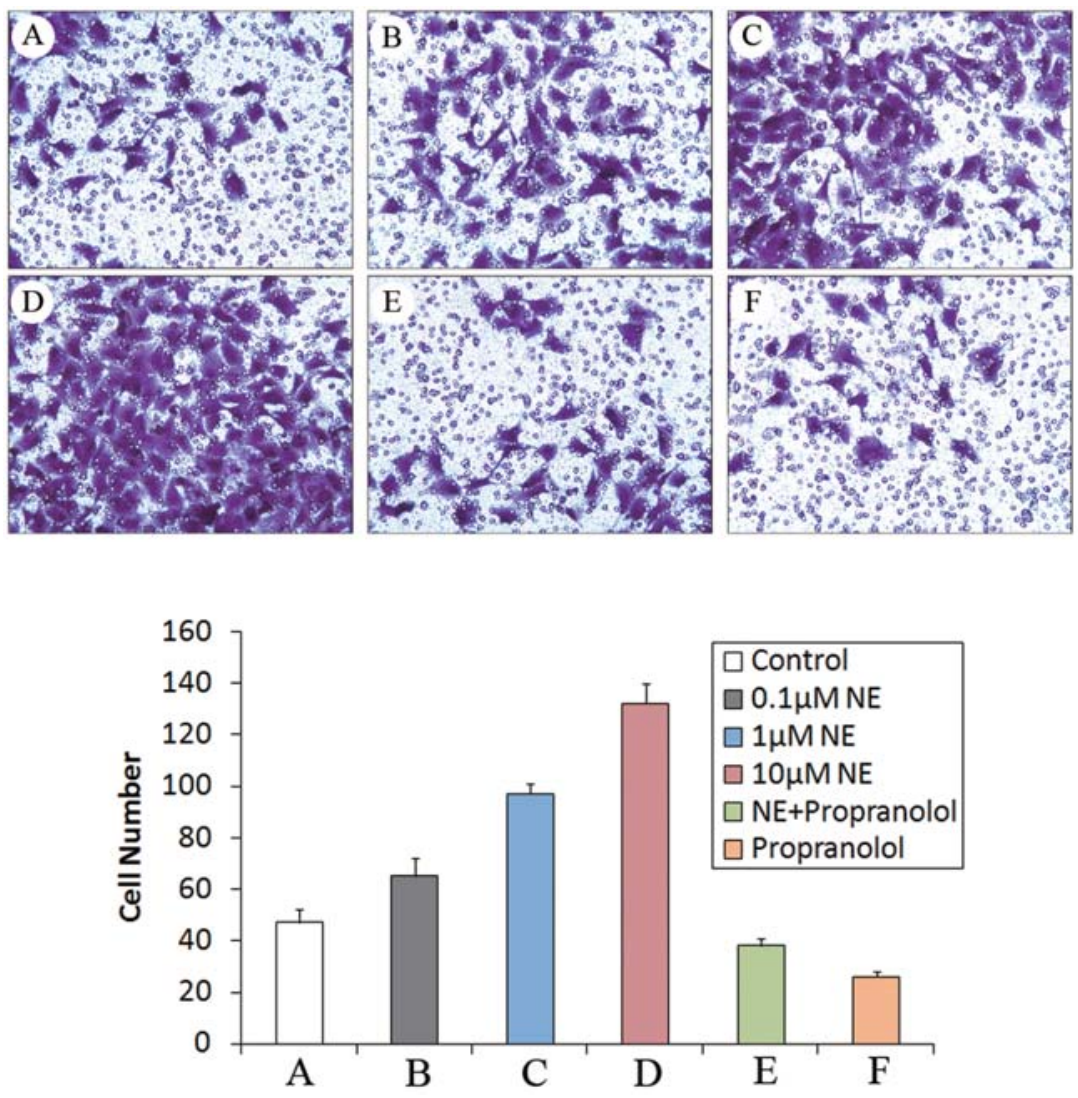

Figure 2. Cell invasion assay in pancreatic cancer cell line Miapaca-2. NE (1 and $10 \mu \mathrm{M})$ significantly $(\mathrm{P}<0.05)$ stimulated cell invasion, an effect completely blocked by propranolol. The photograph shows the bottom side of the filter inserts with cells that have migrated through the filter pores. Columns in the graph are the diagram of the count analysis. 


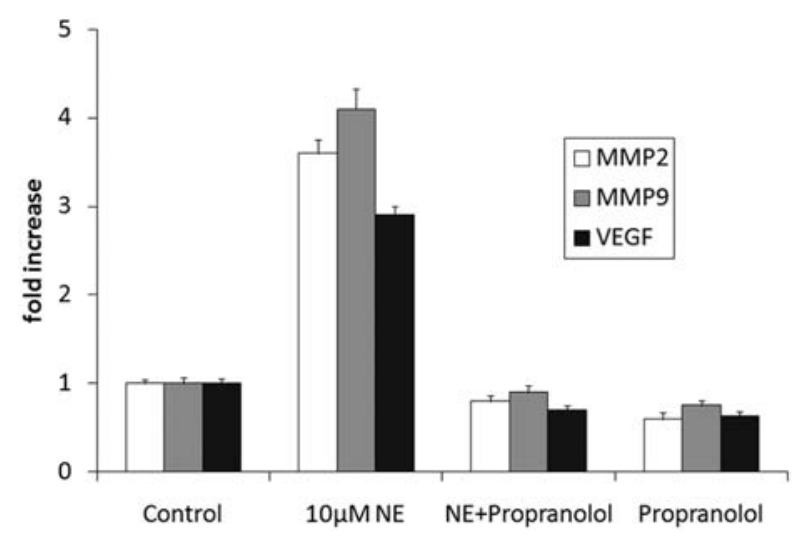

Figure 3. NE $(10 \mu \mathrm{M})$ significantly $(\mathrm{P}<0.05)$ increases the MMP-2, MMP-9 and VEGF levels secreted in Miapaca-2 cells. These responses were completely inhibited by preexposure to propranolol. ELISA assays were determined at $24 \mathrm{~h}$ after the treatments. Data are mean values and standard errors of 5 samples per treatment group.

A

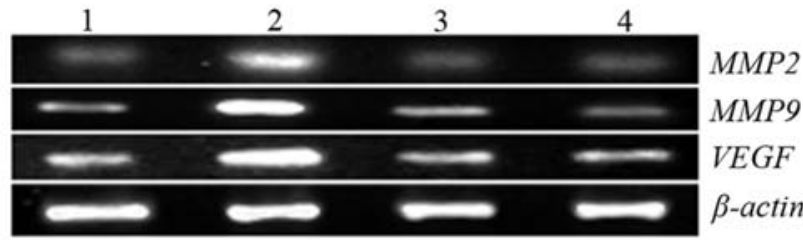

B

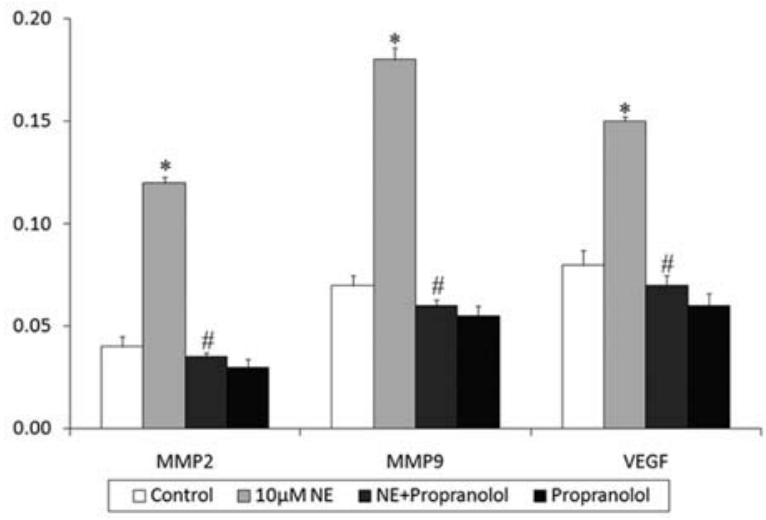

Figure 4. The RT-PCR products about MMP-2, MMP-9 and VEGF mRNA (A). 1, Control group; 2, NE (10 $\mu \mathrm{M})$ group; 3, propranolol followed by NE treatment group; 4, propranolol group. (B) The ratios of target products over $\beta$-actin. Data represent mean $\pm \mathrm{SD}$ of 3 different experiments. ${ }^{*} \mathrm{P}<0.05$ as compared with control group, ${ }^{\#} \mathrm{P}<0.05$ as compared with $\mathrm{NE}$ group.

Propranolol inhibits NE-mediated increase of MMP-2, $M M P-9$ and VEGF levels in human pancreatic cancer cells. We examined the effect of NE on the secretion of MMP-2, MMP-9, and VEGF in Miapaca-2 cells. Our results showed that NE dramatically increased the levels of MMP-2, MMP-9, and VEGF at $24 \mathrm{~h}$ post treatment (Fig. 3). NE $(10 \mu \mathrm{M})$ induced a $\sim 3$.6-fold, $\sim 4$.1-fold and $\sim 2$.9-fold increase in the MMP-2, MMP-9, and VEGF levels in the Miapaca-2 supernatant at $24 \mathrm{~h}$ post-stimulation. The RT-PCR results showed that the MMP-2, MMP-9, and VEGF gene expression were significant up-regulation after treatment with $10 \mu \mathrm{M}$ $\mathrm{NE}$ for $24 \mathrm{~h}$ (Fig. 4). The data suggest that the increase in the levels of MMP-2, MMP-9, and VEGF protein was a result of transcriptional changes. Since the B-blocker, propranolol, has been shown to have inhibitory effects on NE-mediated increases in cell invasiveness of human pancreatic cancer cells, we also explored its ability to inhibit MMP-2, MMP-9, and VEGF. Interestingly, our results showed that propranolol reduced the increased levels of secreted MMP-2, MMP-9 and VEGF levels in NE-stimulated Miapaca-2 cells (Figs. 3 and 4). This suggests that propranolol abrogated NE-induced upregulation of MMP-2, MMP-9, and VEGF release, indicating that the action of NE on pancreatic cancer cell invasiveness was through B-ARs.

\section{Discussion}

In this study, we addressed the effect of NE, which belongs to the group of classical neurotransmitters, on the invasiveness of pancreatic cancer cells, which is a critical component of the metastatic cascade. Our data show that NE can significantly enhance the capacity of the pancreatic cancer cells to invade the extracellular matrix that is characteristic of the basement membrane. Furthermore, we showed that NE can up-regulate the production of MMP-2, MMP-9, and VEGF in the Miapaca- 2 cells. These factors, which are responsible for the invasiveness and angiogenic responses, facilitate penetration of the extracellular matrix of the pancreatic cancer cells. We also showed that treatment with the $\beta$-blocker, propranolol, to block the binding of NE to B-ARs suppresses the invasiveness of Miapaca-2 cells and abrogates the up-regulation of MMP-2, MMP-9, and VEGF. These data suggest that NE plays a role in the invasiveness of pancreatic cancer cells, and B-blocker may be used for the chemoprevention of pancreatic cancer metastasis.

Tumor cell migration and invasion, the prerequisite for metastasis development, are not only merely genetically determined but are also distinctly regulated by signal substances in the environment, including chemokines and neurotransmitters (4-7). It is well known that chemokines regulate the migratory activity and homing of leukocytes (21). Recently, it has become evident that chemokines are also involved in the development of metastasis and localization of cancer cells $(22,23)$. Neurotransmitters are signal substances that traditionally have functions in both the central and peripheral nervous systems. The pancreas is richly supplied with nerves. Deriving from different locations, nerve fibers of different types intermingle as they enter or leave the pancreas, frequently closely adherent to pancreatic arteries (24). Current studies have revealed that neurotransmitters have direct influence on the migratory activity and invasiveness of tumor cells (6). NE belongs to the group of classical neurotransmitters. It can modulate carcinogenesis induced by a tobacco-specific nitrosamine in the lungs of hamsters (25). It can also activate the migration and invasion of carcinoma cells in cancers of the breast (13) and the colon (14). Furthermore, NE induces chemotaxis in breast carcinoma cells (13), and metastases of small-cell lung carcinoma (SCLC) are very common in the NE-producing adrenal glands and the brain (26). Overexpression of NE has recently been described in the majority of investigated human pancreatic cancers (27), a finding that strengthens the significance of NE on cancer progression. In our study, we observed that exogenous NE stimulates the 
invasiveness of the pancreatic cancer cells in a concentrationdependent manner. This indicated that the invasiveness of pancreatic cancer cells was distinctly regulated by NE. NE is a neurotransmitter that is also released in stress reactions. The long-lasting elevation of catecholamines attributable to chronic stress is known to be a risk factor for cancers (28). Thus, we also provide evidence for a functional link between chronic stress and its influence on pancreatic cancer cells.

The process of tumor cell penetration of the host basement membrane consists of attachment, matrix dissolution, motility, and penetration (29). The ability of tumor cells to invade the extracellular matrix plays an important role in invasion and metastasis. MMPs are key factors in the degradation of the components of the extracellular matrix, such as collagen, laminins, fibronectins, elastins, and the protein core of proteoglycans (30). The coexpression of MMPs and VEGF has been described in many human cancers. High levels of VEGF and MMPs have been described in patients with ovarian cancer (31). The level of VEGF has been shown to be positively correlated with those of MT1-MMP, MMP-2, and MMP-9 in human glioblastomas (32). Studies have indicated that levels of MMP-9 and VEGF are positively correlated in head and neck squamous cell carcinoma (33). In our study, we found that NE had a role in modulating the expression of MMP-2, MMP-9, and VEGF in pancreatic cancer cells. The NE-mediated up-regulation of MMP-2, MMP-9, and VEGF contributed to the aggressiveness of the highly metastatic forms of pancreatic cancer cells.

$\beta_{1}$-AR and $\beta_{2}$-AR were expressed in the pancreatic cancer cells. Evidence supporting the role of these receptors in the NE-dependent effect is provided by our results showing that propranolol inhibited the NE-dependent invasiveness of cells and the up-regulation of MMP-2, MMP-9, and VEGF release. B-ARs antagonists have been used as therapies for hypertension and the prevention of heart attacks for many years. Increasing evidence suggests that patients with pancreatic cancer share many risk factors with cardiovascular disease patients, such as smoking and a high-fat diet (34). Therefore, our findings might open new pharmacological possibilities for the preventive treatment of pancreatic cancer, i.e., to delay or to inhibit the progression of the disease with regard to invasion and the development of metastases. However, further approaches to inhibit pancreatic cancer cells invasion and the relevant signal transduction pathways remain to be elucidated, and whether NE leads to organspecific metastasis to other NE-rich organs remains to be investigated.

In summary, our results show that NE, which belongs to the group of classical neurotransmitters, can directly enhance the invasive potential of pancreatic cancer cells via B-ARs by mediating the up-regulation of MMP-2, MMP-9, and VEGF, and this effect can be inhibited by the B-blocker, propranolol. These results support the theory that the development of metastases is not only genetically determined but is also influenced by signal substances in the tumor environment. This study also provides experimental evidence for the use of $\beta$-blockers for chemoprevention of pancreatic cancer metastasis.

\section{References}

1. Ito $Y$, Aiura K, Ueda M, Kitajima M and Kitagawa Y: Establishment of combined immuno-chemotherapy with systemically administered gemcitabine and intra-portal administration of interleukin-2 in murine models of liver metastases of pancreatic cancer. Int J Oncol 33: 49-58, 2008.

2. Fearon ER and Vogelstein B: A genetic model for colorectal tumorigenesis. Cell 61: 759-767, 1990.

3. Miyaki M, Iijima T, Konishi M, Sakai K, Ishii A, Yasuno M, Hishima T, Koike M, Shitara N, Iwama T, Utsunomiya J, Kuroki $\mathrm{T}$ and Mori T: Higher frequency of Smad4 gene mutation in human colorectal cancer with distant metastasis. Oncogene 18: 3098-3103, 1999.

4. Balkwill $\mathrm{F}$ and Mantovani A: Inflammation and cancer: back to Virchow? Lancet 357: 539-545, 2001

5. Liotta LA: An attractive force in metastasis. Nature 410: 24-25, 2001.

6. Entschladen F, Drell TL, Lang K, Joseph J and Zaenker KS: Tumour-cell migration, invasion, and metastasis: navigation by neurotransmitters. Lancet Oncol 5: 254-258, 2004.

7. Entschladen F, Lang K, Drell TL, Joseph J and Zaenker KS: Neurotransmitters are regulators for the migration of tumor cells and leukocytes. Cancer Immunol Immunother 51: 467-482, 2002.

8. Palm D, Lang K, Niggemann B, Drell TL, Masur K, Zaenker KS and Entschladen F: The norepinephrine-driven metastasis development of PC-3 human prostate cancer cells in BALB/c nude mice is inhibited by beta-blockers. Int J Cancer 118: 2744-2749, 2006.

9. Sood AK, Bhatty R, Kamat AA, Landen CN, Han L, Thaker PH, Li Y, Gershenson DM, Lutgendorf S and Cole SW: Stress hormone-mediated invasion of ovarian cancer cells. Clin Cancer Res 12: 369-375, 2006.

10. Lutgendorf SK, Johnsen EL, Cooper B, Anderson B, Sorosky JI, Buller RE and Sood AK: Vascular endothelial growth factor and social support in patients with ovarian carcinoma. Cancer 95: 808-815, 2002.

11. Lutgendorf SK, Cole S, Costanzo E, Bradley S, Coffin J, Jabbari S, Rainwater K, Ritchie JM, Yang M and Sood AK: Stress-related mediators stimulate vascular endothelial growth factor secretion by two ovarian cancer cell lines. Clin Cancer Res 9: 4514-4521, 2003

12. Wu W, Yamaura T, Murakami K, Ogasawara M, Hayashi K, Murata J and Saiki I: Involvement of TNF-alpha in enhancement of invasion and metastasis of colon 26-L5 carcinoma cells in mice by social isolation stress. Oncol Res 11: 461-469, 1999.

13. Drell TL, Joseph J, Lang K, Niggemann B, Zaenker KS and Entschladen F: Effects of neurotransmitters on the chemokinesis and chemotaxis of MDA-MB-468 human breast carcinoma cells. Breast Cancer Res Treat 80: 63-70, 2003.

14. Masur K, Niggemann B, Zanker KS and Entschladen F: Norepinephrine-induced migration of SW 480 colon carcinoma cells is inhibited by beta-blockers. Cancer Res 61: 2866-2869, 2001.

15. Lang K, Drell TL, Lindecke A, Niggemann B, Kaltschmidt C, Zaenker KS and Entschladen F: Induction of a metastatogenic tumor cell type by neurotransmitters and its pharmacological inhibition by established drugs. Int J Cancer 112: 231-238, 2004.

16. Parkin DM, Bray F, Ferlay J and Pisani P: Estimating the world cancer burden: Globocan 2000. Int J Cancer 94: 153-156, 2001.

17. Jemal A, Siegel R, Ward E, Hao Y, Xu J, Murray T and Thun MJ: Cancer statistics, 2008. CA Cancer J Clin 58: 71-96, 2008.

18. Weddle DL, Tithoff P, Williams M and Schuller HM: Betaadrenergic growth regulation of human cancer cell lines derived from pancreatic ductal carcinomas. Carcinogenesis 22: 473-479, 2001.

19. Askari MD, Tsao MS and Schuller HM: The tobacco-specific carcinogen, 4-(methylnitrosamino)-1-(3-pyridyl)-1-butanone stimulates proliferation of immortalized human pancreatic duct epithelia through beta-adrenergic transactivation of EGF receptors. J Cancer Res Clin Oncol 131: 639-648, 2005.

20. Zhang D, Ma Q, Shen S and Hu H: Inhibition of pancreatic cancer cell proliferation by propranolol occurs through apoptosis induction: the study of beta-adrenoceptor antagonist's anticancer effect in pancreatic cancer cell. Pancreas 38: 94-100, 2009.

21. Kunkel EJ and Butcher EC: Chemokines and the tissue-specific migration of lymphocytes. Immunity 16: 1-4, 2002. 
22. Muller A, Homey B, Soto H, Ge N, Catron D, Buchanan ME, McClanahan T, Murphy E, Yuan W, Wagner SN, Barrera JL, Mohar A, Verastegui E and Zlotnik A: Involvement of chemokine receptors in breast cancer metastasis. Nature 410 : 50-56, 2001.

23. Payne AS and Cornelius LA: The role of chemokines in melanoma tumor growth and metastasis. J Invest Dermatol 118: 915-922, 2002.

24. Bockman DE: Nerves in the pancreas: what are they for? Am J Surg 194: 61-64, 2007.

25. Schuller HM, Porter B and Riechert A: Beta-adrenergic modulation of NNK-induced lung carcinogenesis in hamsters. J Cancer Res Clin Oncol 126: 624-630, 2000.

26. Schouten LJ, Rutten J, Huveneers HA and Twijnstra A: Incidence of brain metastases in a cohort of patients with carcinoma of the breast, colon, kidney, and lung and melanoma. Cancer 94: 2698-2705, 2002.

27. Schuller HM, Al-Wadei HA and Majidi M: GABA B receptor is a novel drug target for pancreatic cancer. Cancer 112: 767-778, 2008.

28. Paredes A, Galvez A, Leyton V, Aravena G, Fiedler JL, Bustamante D and Lara HE: Stress promotes development of ovarian cysts in rats: the possible role of sympathetic nerve activation. Endocrine 8: 309-315, 1998.
29. Liotta LA and Kohn EC: The microenvironment of the tumourhost interface. Nature 411: 375-379, 2001.

30. Curran S and Murray GI: Matrix metalloproteinases: molecular aspects of their roles in tumour invasion and metastasis. Eur J Cancer 36: 1621-1630, 2000.

31. Belotti D, Paganoni P, Manenti L, Garofalo A, Marchini S, Taraboletti G and Giavazzi R: Matrix metalloproteinases (MMP9 and MMP2) induce the release of vascular endothelial growth factor (VEGF) by ovarian carcinoma cells: implications for ascites formation. Cancer Res 63: 5224-5229, 2003.

32. Munaut C, Noel A, Hougrand O, Foidart JM, Boniver J and Deprez M: Vascular endothelial growth factor expression correlates with matrix metalloproteinases MT1-MMP, MMP-2 and MMP-9 in human glioblastomas. Int J Cancer 106: 848-855, 2003.

33. Lim SC: Expression of c-erbB receptors, MMPs and VEGF in head and neck squamous cell carcinoma. Biomed Pharmacother 59 (Suppl. 2): S366-S369, 2005.

34. Lowenfels AB and Maisonneuve P: Epidemiology and prevention of pancreatic cancer. Jpn J Clin Oncol 34: 238-244, 2004. 